\title{
ISOLATION AND CHARACTERIZATION OF MULTIDRUG RESISTANT BETA-LACTAMASE PRODUCING SALMONELLA ENTERICA FROM WILD MIGRATORY BIRDS
}

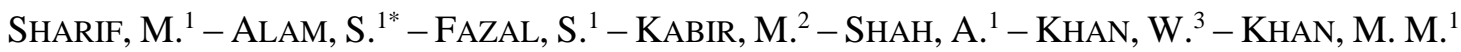 \\ - KHURSHID, A. ${ }^{4}$ \\ ${ }^{I}$ Department of Microbiology, The University of Haripur, Haripur, Pakistan \\ ${ }^{2}$ Department of Forestry and Wildlife Management, The University of Haripur, Haripur, Pakistan \\ ${ }^{3}$ Department of Biotechnology, COMSATS University Islamabad, Abbottabad Campus, \\ Abbottabad, Pakistan \\ ${ }^{4}$ Department of Biochemistry, Hazara University, Mansehra, Pakistan \\ *Corresponding author \\ e-mail: sadia.alam2004@gmail.com
}

(Received $14^{\text {th }}$ Sep 2019; accepted $8^{\text {th }}$ Jan 2020)

\begin{abstract}
A multidrug resistant, an enteric pathogen, Salmonella enterica is the most frequent cause of food poisoning. They are gram negative, aerobic or facultative anaerobic bacteria belonging to the family Enterobacteriacae. Migratory birds serve as key factor, may disseminate Salmonella to the susceptible people through shared environment, fecal shedding and by mean of direct contact. The aim of present study was to investigate the occurrence of beta-lactamase genes (CTX-M and TEM) within antibiotic resistant strains of Salmonella enterica isolated from migratory birds. Present study incorporated isolation of 60 samples of Salmonella enterica from saliva, intestinal fluid and blood of different migratory birds. They are catalase positive, oxidase negative and $\mathrm{H}_{2} \mathrm{~S}$ gas producer. The antibiotic resistance of all isolated strains (29) was tested against 10 antibiotics by Kirby-Bauer disc diffusion method. The antibiotics that were used include ciprofloxacin $(5 \mu \mathrm{g})$, ceftriaxone $(30 \mu \mathrm{g})$, meropenam $(10 \mu \mathrm{g})$, aztreonam $(30 \mu \mathrm{g})$, penicillin $(10 \mu \mathrm{g})$, erythromycin $(15 \mu \mathrm{g})$, streptomycin $(10 \mu \mathrm{g})$, gentamycin $(10 \mu \mathrm{g})$, vancomycin $(10 \mu \mathrm{g})$ and imipenem $(10 \mu \mathrm{g})$. These strains indicated more resistance towards penicillin $(93 \%)$, streptomycin $(100 \%)$, erythromycin (93\%), aztreonam (62\%) and vancomycin (90\%) and low resistance towards ciprofloxacin (21\%), ceftriaxone (54\%) and imepenam (45\%). For the detection of CTX-M and TEM gene in ciprofloxacin and ceftriaxone resistant strains, DNA was obtained through chemical method. These strains were further checked for the presence of CTX-M and TEM gene by polymerase chain reaction (PCR). PCR results demonstrated that all the strains contain TEM gene but CTX-M gene was not identified in any of these strains. PCR amplified product was sequenced, followed by BLAST, which confirmed the presence of TEM gene giving resistance to beta-lactam antibiotics.
\end{abstract}

Keywords: Salmonella enterica, TEM gene, antimicrobial resistance, CTX-M gene, polymerase chain reaction (PCR), BLAST

Abbreviations: SS agar: Salmonella Sheila agar, DNA: Deoxyribonucleic acid, STE buffer: Sodium Chloride-Tries-EDTA, TE buffer: Tries-EDTA, PCR: Polymerase Chain Reaction, CIP: Ciprofloxacin, CRO: Ceftriaxone, MEM: Meropenam, ATM: Aztreonam, S: Streptomycin, E: Erythromycin, P: Penicillin, CN: Gentamicin, VA: Vancomycin, IPM: Imipenem, BLAST: Basic Local Alignment Search Tool

\section{Introduction}

The bacterial genus Salmonella which is an enteric pathogen causes a wide spectrum of disease (Acheson and Hohmann, 2001). Salmonella enterica is mostly responsible for food poisoning (Herikstad et al., 2002). Salmonella is an exceptionally assorted family, 
which contain two species that are $S$. bongori and S. enterica (Tindall et al., 2005). S. bongori infects mostly ectotherms and unusually humans while $S$. enterica incorporates around 2500 serovars (Brenner et al., 2000). It is subdivided into 6 subspecies enterica, arizonae, diarizonae, salamae, indica and houtenae dependent on biochemistry and genomics (Malorny et al., 2011). The normal characteristic environment for subspecies enterica is endotherms while for the subspecies salamae, arizonae, diari zonae, houtenae, indica and S. bongori is ectotherms and environment. Migratory birds may serve as vehicle for the transmission of various extrinsic microorganisms (Maeda et al., 2001). Salmonella have been isolated from wildlife including exotic birds (Refsum et al., 2002). Gourmelon et al. (2010) have also observed that aquatic system gets polluted by fecal material of these exotic species can lead to human infection. During annual migration, migratory birds move from one place to another in search of suitable weather and food and play an important role in causing infections in humans and animals (Foti et al., 2011). They can easily be transmitted through contaminated food and water, improper hygienic conditions and improper disposal of sewage. Antimicrobial resistance in Salmonella takes place due to horizontal and vertical transference of antimicrobial gene, inappropriate self-medication which leads to resistance in microorganisms against chemical, therapeutic agents (White et al., 2002). The excessive use of antimicrobials has brought about a development of antibiotic resistance in humans, animals and environment (Berendonk et al., 2015; Radhouani et al., 2014). Majority of ceftriaxone and ciprofloxacin resistance was because of the action of $\beta$ lactamase gene. The horizontal gene transfer plays an important part in expanding ceftriaxone and ciprofloxacin resistance.

The main objective of present study was to isolate different strains of Salmonella from oral, intestinal and blood samples of migratory birds and to investigate the occurrence of beta-lactamase genes (CTX-M and TEM) which give antibiotic resistance against beta-lactam antibiotics (ciprofloxacin and ceftriaxone).

\section{Material and methods}

\section{Study design}

This study involved biochemical identification of Salmonella enterica from blood, nasal and intestinal fluid of migratory birds and molecular characterization and PCR detection of $\beta$-lactamase (CTX-M and TEM) genes.

\section{Sample collection}

Oral, intestinal and blood samples were collected from different seasonal avian species at watery sites of Hazara division (Tarbela Lake, Chakai, Siran Valley, and Khanpur). During period from September 2018 till February 2019, migratory birds were captured for study by licensed hunters from different watery sites of Hazara division. A sterile culturette was used to collect samples. A total of 60 samples were collected by rubbing swabs to oral, intestine and blood of different migratory birds. 47 blood samples were obtained through sterile syringes while 6 swabs from saliva and 7 swabs from intestinal fluid were obtained. After sampling, the culturettes were placed in their plastic sheath having nutrient broth and kept in refrigerator at $4{ }^{\circ} \mathrm{C}$. Then the samples were enriched by adding peptone water and incubated at $37{ }^{\circ} \mathrm{C}$ for $24 \mathrm{~h}$. After incubation, the pre-enriched samples were examined for the presence of Salmonella. 


\section{Isolation and identification}

The samples were inoculated on sterile petri plates containing Salmonella Shigella agar and incubated at $37{ }^{\circ} \mathrm{C}$ for $24 \mathrm{~h}$. The isolated colonies were picked up and again streaked on $S S$ agar medium to obtain a pure culture. Purified bacterial colonies were exposed to cultural, colony morphology and biochemical identification by using catalase, oxidase and citrate test.

\section{Antibiotic sensitivity}

Antibiotic Sensitivity of 29 positive isolates of Salmonella enterica to 10 antibiotics was checked on Muller Hinton agar by Kirby-Bauer disc diffusion method. A fresh colony of Salmonella was picked up from the culture plate and spread over the entire petri plate containing Muller Hinton agar by using sterile cotton swab. Ten antibiotics with different concentrations were used which included ciprofloxacin, ceftriaxone, penicillin, erythromycin, streptomycin, vancomycin, gentamicin, imipenem, meropenam and aztreonam. The antimicrobial disks were placed on the surface of agar with the help of forceps and plates were incubated overnight at a temperature of $37^{\circ} \mathrm{C}$. After incubation, the zone diameters were measured to nearest millimeter and classified as sensitive (S), intermediate (I) and resistant (R) according to European Committee on Antimicrobial Susceptibility Testing (EUCAST) (Table 1).

Table 1. Concentration $(\mu \mathrm{g})$ and breakpoints $(\mathrm{mm})$ of antibiotics

\begin{tabular}{c|c|c|c|c}
\hline \multirow{2}{*}{ Antibiotics } & \multirow{2}{*}{ Disc code } & \multirow{2}{*}{ Potency $(\boldsymbol{\mu g})$} & \multicolumn{2}{|c}{ Zone diameter breakpoint $(\mathbf{m m})$} \\
\cline { 3 - 5 } & & $\mathbf{S} \geq$ & $\mathbf{R}<$ \\
\hline Ciprofloxacin & CIP & 5 & 22 & 19 \\
Ceftriaxone & CRO & 30 & 23 & 20 \\
Penicillin & P & 10 & 14 & 15 \\
Erythromycin & E & 15 & 21 & 15 \\
Streptomycin & S & 10 & 15 & 11 \\
Vancomycin & VA & 10 & 17 & 14 \\
Gentamicin & CN & 10 & 17 & 14 \\
Imipenem & IPM & 10 & 22 & 16 \\
Meropenam & MEM & 10 & 22 & 16 \\
Aztreonam & ATM & 30 & 24 & 21 \\
\hline
\end{tabular}

\section{DNA extraction}

DNA was extracted by chemical method (Ausubel et al., 1994). The $1 \mathrm{ml}$ growth culture of bacterial suspension was incubated overnight and centrifuged at $8000 \mathrm{~g}$ for 2 min. Supernatant was removed. $400 \mu \mathrm{S} \mathrm{STE} \mathrm{buffer} \mathrm{was} \mathrm{added} \mathrm{twice} \mathrm{and} \mathrm{cells} \mathrm{were}$ centrifuged at $8000 \mathrm{~g}$ for $2 \mathrm{~min}$. Supernatant was discarded again and $200 \mu \mathrm{TE}$ buffer was added to the pellets. Then, $100 \mu 1$ Tris-saturated phenol was added and tubes were vortexed for $1 \mathrm{~min}$. Samples were centrifuged at $13,000 \mathrm{~g}$ for $5 \mathrm{~min}$ at $4{ }^{\circ} \mathrm{C}$ so that the aqueous phase is separated from organic phase. Then $40 \mu \mathrm{TE}$ buffer was added to $160 \mu 1$ upper aqueous phase and mixed with $100 \mu \mathrm{l}$ chloroform and centrifuged at $13,000 \mathrm{~g}$ for $5 \mathrm{~min}$ at $4{ }^{\circ} \mathrm{C} .150 \mu \mathrm{l}$ upper aqueous phase was taken into clean eppendorf tube and that contained the required purified DNA. 


\section{Polymerase chain reaction (PCR)}

PCR was performed for DNA amplification on thermocycler (Multigene Optimax, USA). Two sets of primer pairs specific for TEM and CTX-M gene were used (Table 2). The reactions were performed in final volume of $25 \mu \mathrm{L}$ that involved $3 \mu \mathrm{L}$ of DNA template, $1 \mu \mathrm{L}$ of forward primer, $1 \mu \mathrm{L}$ of reverse primer, $10 \mu \mathrm{L}$ of $5 \mathrm{X}$ FIREPol ${ }^{\circledR}$ master mix (FIREPol ${ }^{\circledR}$ DNA Polymerase, $5 \mathrm{X}$ reaction buffer B $(0.4 \mathrm{M}$ Tris- $\mathrm{HCl}, 0.1 \mathrm{M}$ $\left(\mathrm{NH}_{4}\right)_{2} \mathrm{SO}_{4}, 0.1 \%$ w/v Tween 20), $7.5 \mathrm{mM} \mathrm{MgCl} 2,1 \mathrm{mM}$ dNTPs of each dATP, dGTP, dCTP, dTTP) (Solis BioDyne) and $10 \mu \mathrm{L}$ of distilled water. Amplification was carried out using optimum conditions as follows: 1 cycle of $5 \mathrm{~min}$ for initial denaturation at $94{ }^{\circ} \mathrm{C}, 35$ cycles of $45 \mathrm{~s}$ for final denaturation at $94{ }^{\circ} \mathrm{C}, 45 \mathrm{~s}$ for annealing at $54{ }^{\circ} \mathrm{C}$, $1 \mathrm{~min}$ for initial extension at $72{ }^{\circ} \mathrm{C}$ and 1 cycle of $10 \mathrm{~min}$ for final extension at $72{ }^{\circ} \mathrm{C}$ in case of CTX-M gene. TEM gene was amplified using the same thermocycler with the exception of annealing at $52^{\circ} \mathrm{C}$ for $45 \mathrm{~s}$.

The amplification products were interpreted by gel electrophoresis. The samples were loaded in $1.2 \%$ gel stained with ethidium bromide $(2 \mu \mathrm{g} / \mathrm{mL})$ with the help of micro pipette and run at $90 \mathrm{~V}$ for $45 \mathrm{~min}$. A 100-bp ladder (Solis BioDyne) was used as molecular weight marker. Gel was placed in Cleaver Scientific UV transilluminator (CSLUVTL312) to visualize the DNA bands under UV light for the presence of target gene.

Table 2. Primers sequence of CTX-M and TEM gene

\begin{tabular}{c|c|c|c|c}
\hline Primers & Target gene & Length & Sequence (5' -3') & References \\
\hline TEM F_5 & \multirow{2}{*}{ TEM } & 20 & 5' TTGGGTGCACGAGTGGGTTA 3' & Gangoue-Pieboji et al., \\
TEM R_5 & & 20 & 5' TAATTGTTGCCGGGAAGCTA 3' & 2005 \\
\hline CTX-M F_5 & \multirow{2}{*}{ CTX-M } & 20 & 5' ACCGCCGATAATTCGCAGAT 3' & Kaftandzieva et al., \\
CTX-M R_5 & & 22 & 5' GATATCGTTGGTGGTGCCATAA 3' & 2011 \\
\hline
\end{tabular}

\section{Statistical analysis}

The Vassar Stats.net was used for Chi Square test $\left(x^{2}\right)$ to estimate significance level between sources of $S$. enterica isolates.

\section{Genome sequencing and BLAST}

Identification of resistant gene was confirmed by genome sequencing. The DNA of isolated strains was sequenced by Sanger sequencing method. The nucleotide sequence was analyzed and compared with sequences available on databases by using Basic Local Alignment Search Tool (BLAST).

\section{Results}

For the isolation of Salmonella enterica, Salmonella Shigella agar was used. Out of 60 samples 29 samples were positive for different serovars of Salmonella enterica and 31 samples were negative. Total isolation frequency of Salmonella enterica was found to be $29 / 60$ (48\%) (Fig. 1).

Out of these 29 samples, 22 (30\%) samples were positive from blood, 3 (27\%) from intestinal fluid and 4 (43\%) from saliva (Fig. 2). 


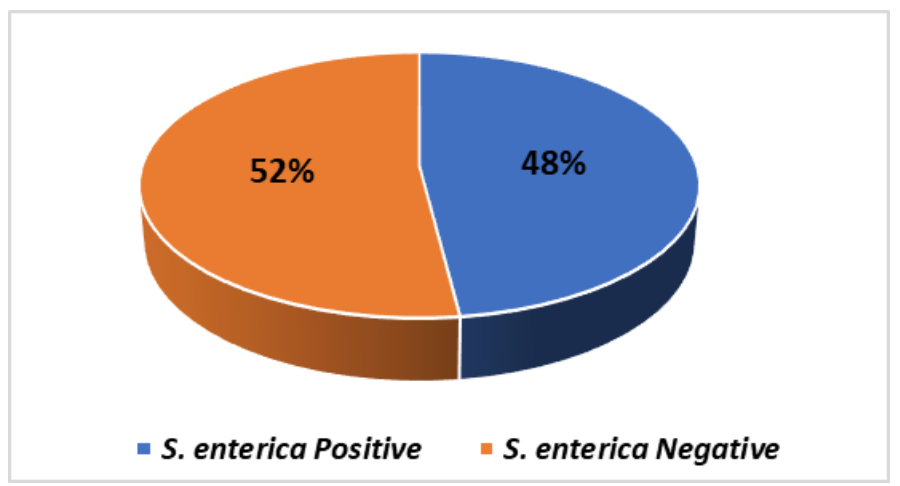

Figure 1. Isolation frequency of Salmonella enterica from migratory birds

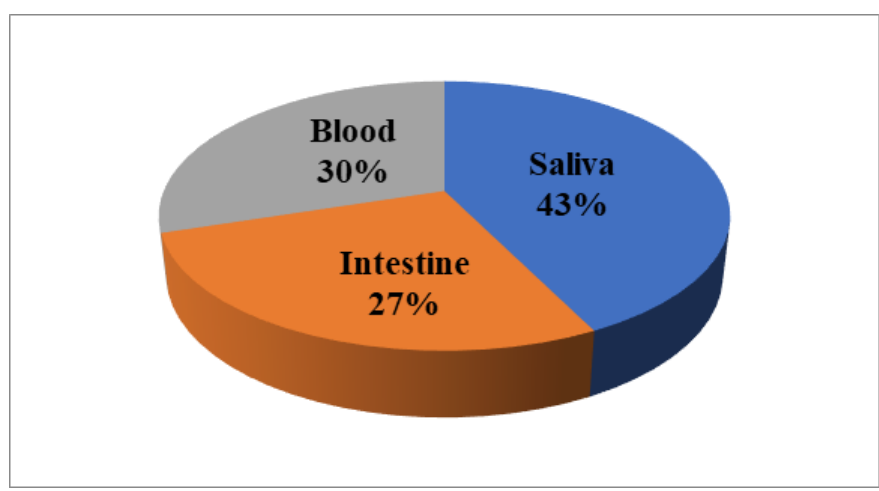

Figure 2. Percentage comparison of migratory birds positive for S. enterica

The chi square test (x) revealed a non-significant difference between sources of $S$. enterica for all antibiotics tested except meropenem where a significant difference was observed $(\mathrm{p}<0.3)$ (Table 3). The pink or yellow with black centered, flat and irregular/smooth colonies were observed on $S S$ agar. The isolated colonies were stained with Gram's stain and appeared as rod shaped and pink in color under microscope (100X) (Fig. 3).

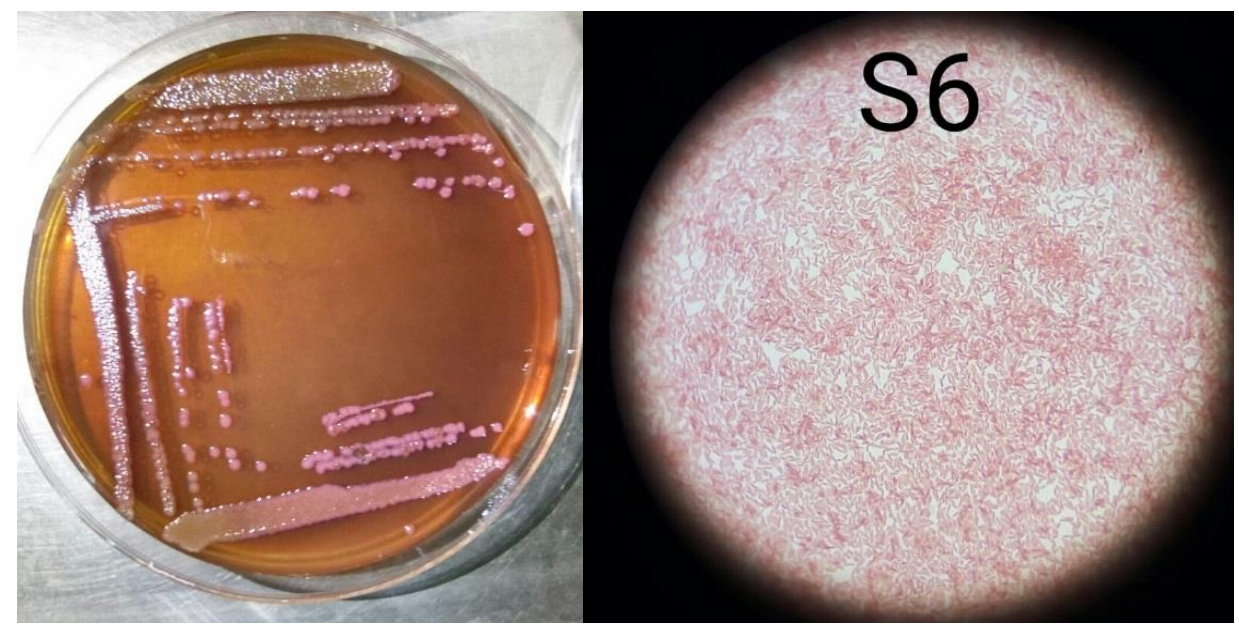

Figure 3. Cultural and microscopic (100X) identification of S. enterica isolated from migratory birds 
All the positive isolates were catalase positive and oxidase negative (Fig. 4).

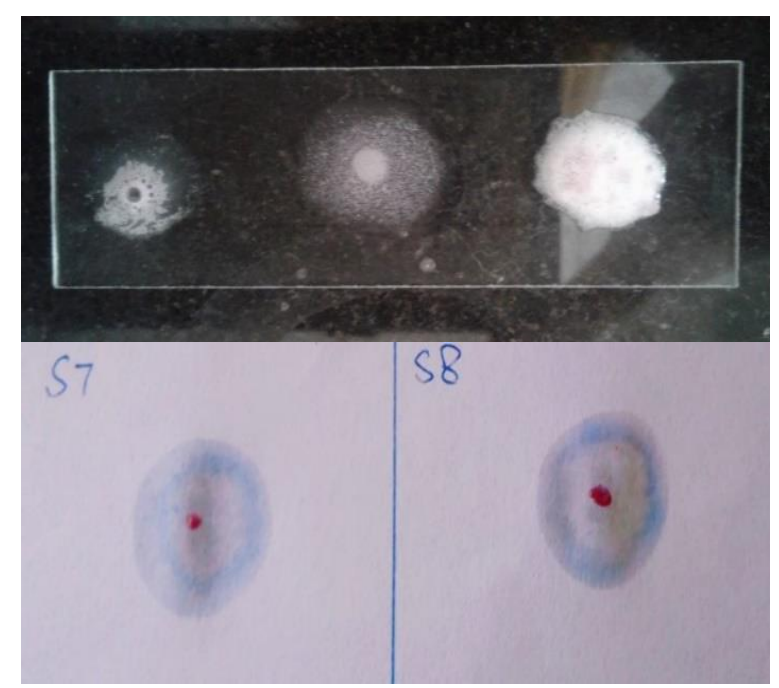

Figure 4. Biochemical identification of Salmonella enterica isolated from migratory birds

The Salmonella enterica serotypes were confirmed by citrate test. Salmonella enterica is citrate positive except S. typhimurium (Fig. 5).

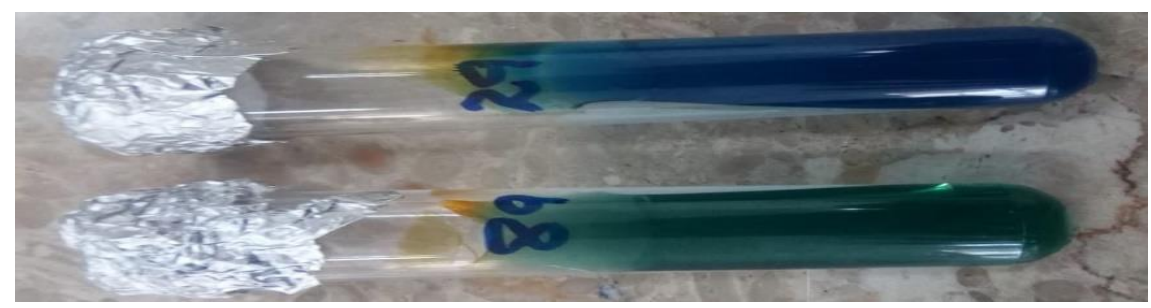

Figure 5. Citrate test for the detection of Salmonella enteric

Antibiotic sensitivity of 29 isolates of Salmonella enterica obtained from saliva $(n=4)$, intestine $(n=3)$ and blood $(n=22)$ was checked against the ten antibiotics. In this study, Salmonella enterica showed resistance towards most antibiotics. The isolated strains showed more resistance against penicillin (93\%), streptomycin (100\%), erythromycin (93\%), vancomycin (90\%), aztreonam (59\%) and meropenam (59\%). They showed low resistance against ciprofloxacin (21\%), ceftriaxone (52\%), imipenem $(45 \%)$ and gentamycin (55\%). 25\% (1/4) resistance was observed against ciprofloxacin and ceftriaxone in saliva samples, $33 \%$ (1/3) resistance against ciprofloxacin and $100 \%$ (3/3) resistance against ceftriaxone was noticed in intestinal fluid and $18 \%(4 / 22)$ resistance against ciprofloxacin and 50\% (11/22) resistance against ceftriaxone were recognized in blood samples of migratory birds (Figs. 6, 7 and 8).

Statistical analysis was performed by chi-square test (Vassarstats.net) with $\mathrm{P}$ values for the comparison of difference between resistance rates of $S$. enterica to different antibiotics among the three sample sources (blood, intestine, saliva) (Table 3). The $\mathrm{P}$ values showed that there were no significant differences in antibiotic prescription patterns between blood, intestine and saliva sample except meropenam (0.03) (P value $<0.05=$ significantly different) . 
Table 3. Chi-square test for comparison of S. enterica resistance rate (\%) to various antibiotics among different sources

\begin{tabular}{c|c|c|c|c|c}
\hline Antibiotics & Blood & Intestine & Saliva & $\mathbf{X}^{\mathbf{2}}$ & P value \\
\hline Ciprofloxacin & $4 / 22(18 \%)$ & $1 / 3(33 \%)$ & $1 / 4(25 \%)$ & 0.42 & 0.81 \\
Ceftriaxone & $11 / 22(50 \%)$ & $3 / 3(100 \%)$ & $1 / 4(25 \%)$ & 3.97 & 0.13 \\
Meropenam & $10 / 22(45 \%)$ & $3 / 3(100 \%)$ & $4 / 4(100 \%)$ & 6.51 & 0.03 \\
Aztreonam & $11 / 22(50 \%)$ & $3 / 3(100 \%)$ & $3 / 4(75 \%)$ & 3.23 & 0.19 \\
Penicillin & $20 / 22(91 \%)$ & $3 / 3(100 \%)$ & $4 / 4(100 \%)$ & 0.68 & 0.71 \\
Erythromycin & $20 / 22(91 \%)$ & $3 / 3(100 \%)$ & $4 / 4(100 \%)$ & 0.68 & 0.71 \\
Streptomycin & $22 / 22(100 \%)$ & $3 / 3(100 \%)$ & $4 / 4(100 \%)$ & 0.00 & 1.00 \\
Gentamycin & $10 / 22(45 \%)$ & $2 / 3(67 \%)$ & $4 / 4(100 \%)$ & 4.25 & 0.11 \\
Vancomycin & $19 / 22(86 \%)$ & $3 / 3(100 \%)$ & $4 / 4(100 \%)$ & 1.06 & 0.58 \\
Imipenem & $8 / 22(36 \%)$ & $2 / 3(67 \%)$ & $3 / 4(75 \%)$ & 2.69 & 0.26 \\
\hline
\end{tabular}

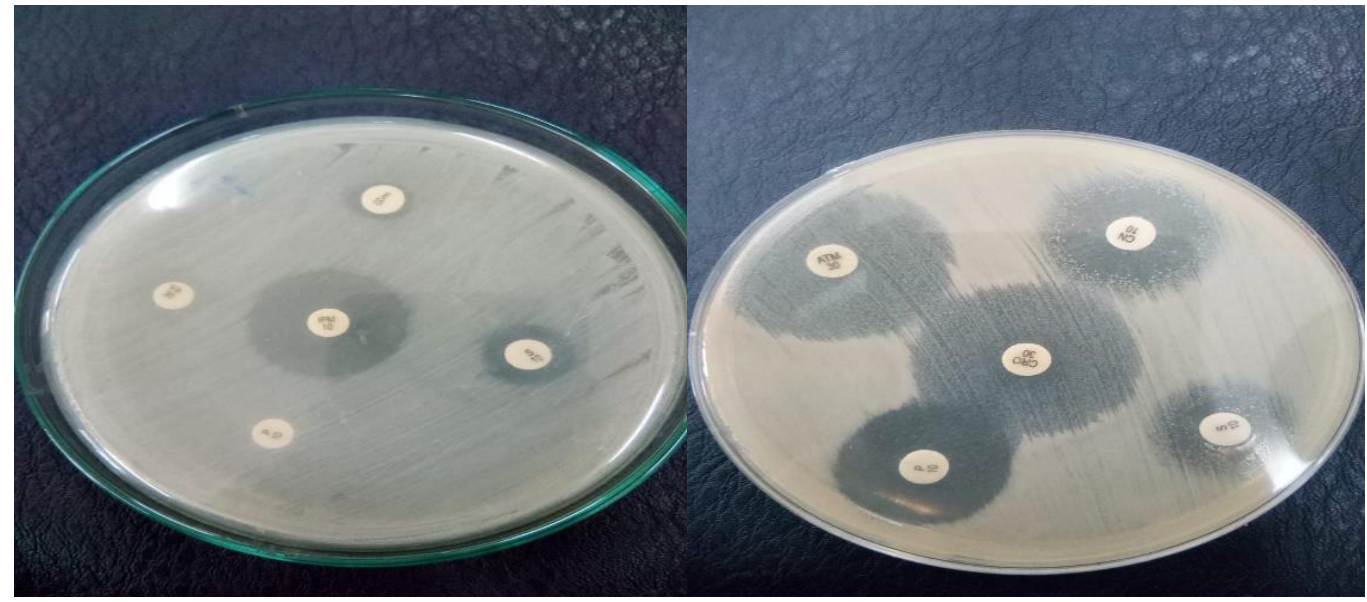

Figure 6. Antibiotic sensitivity of different antibiotics against S. enterica isolates

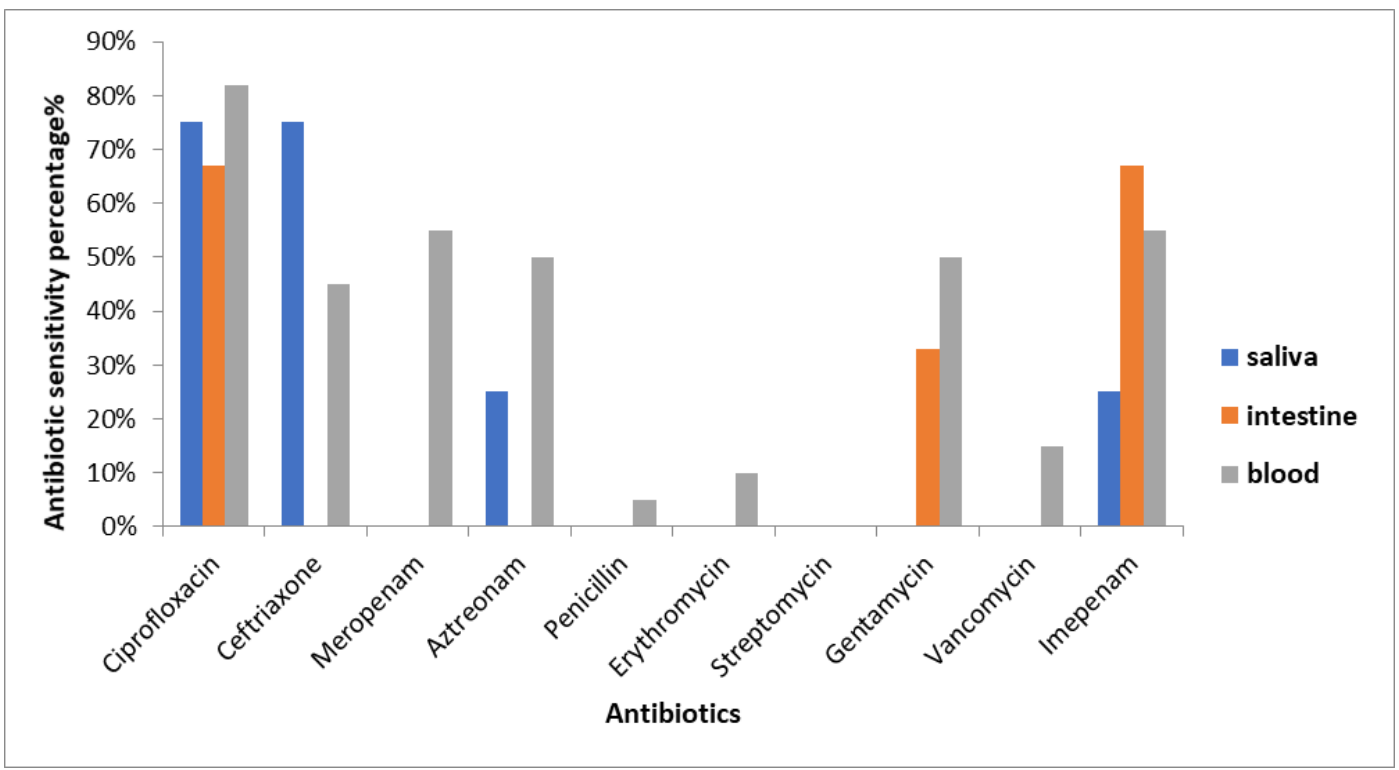

Figure 7. Antibiotic sensitivity pattern of isolates obtained from migratory birds 


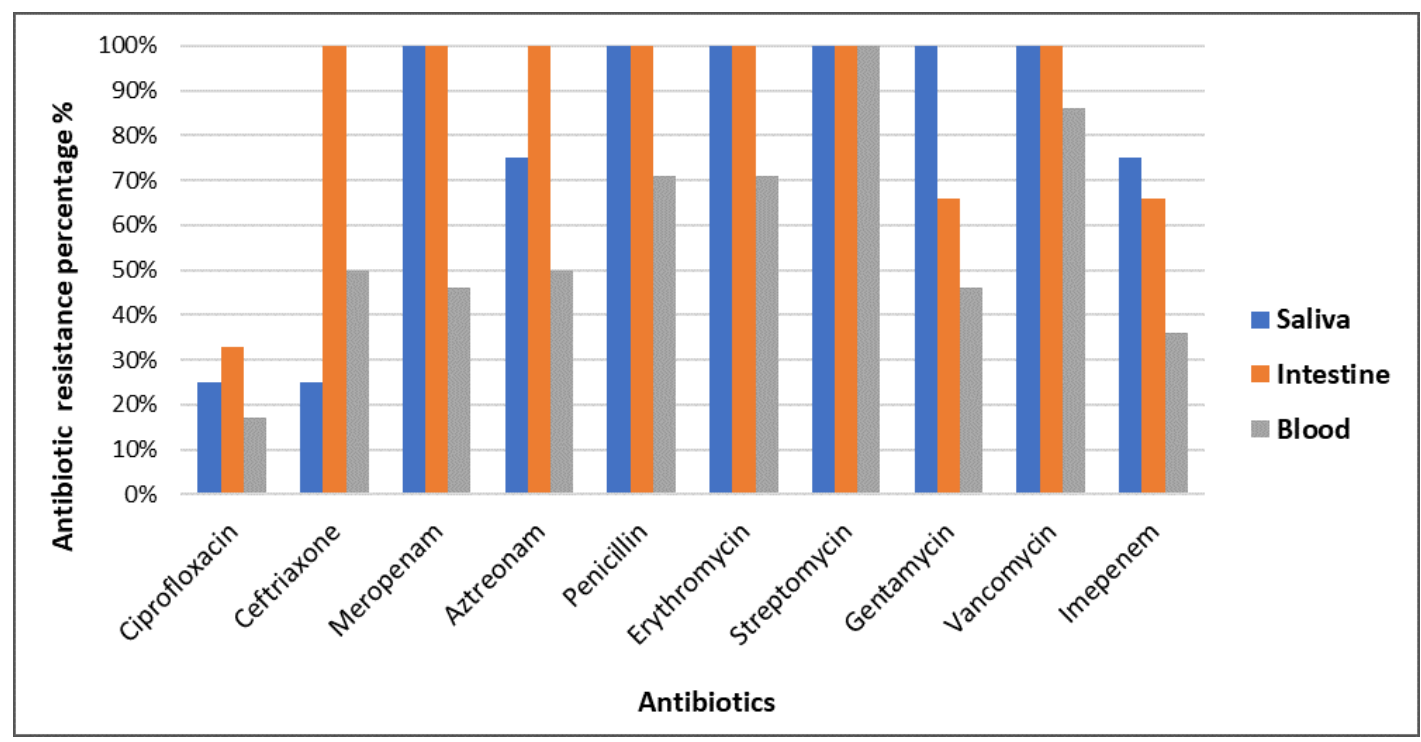

Figure 8. Antibiotic resistance pattern of isolates obtained from migratory birds

The extracted DNA of isolated strains was visualized by using gel electrophoresis (Fig. 9).

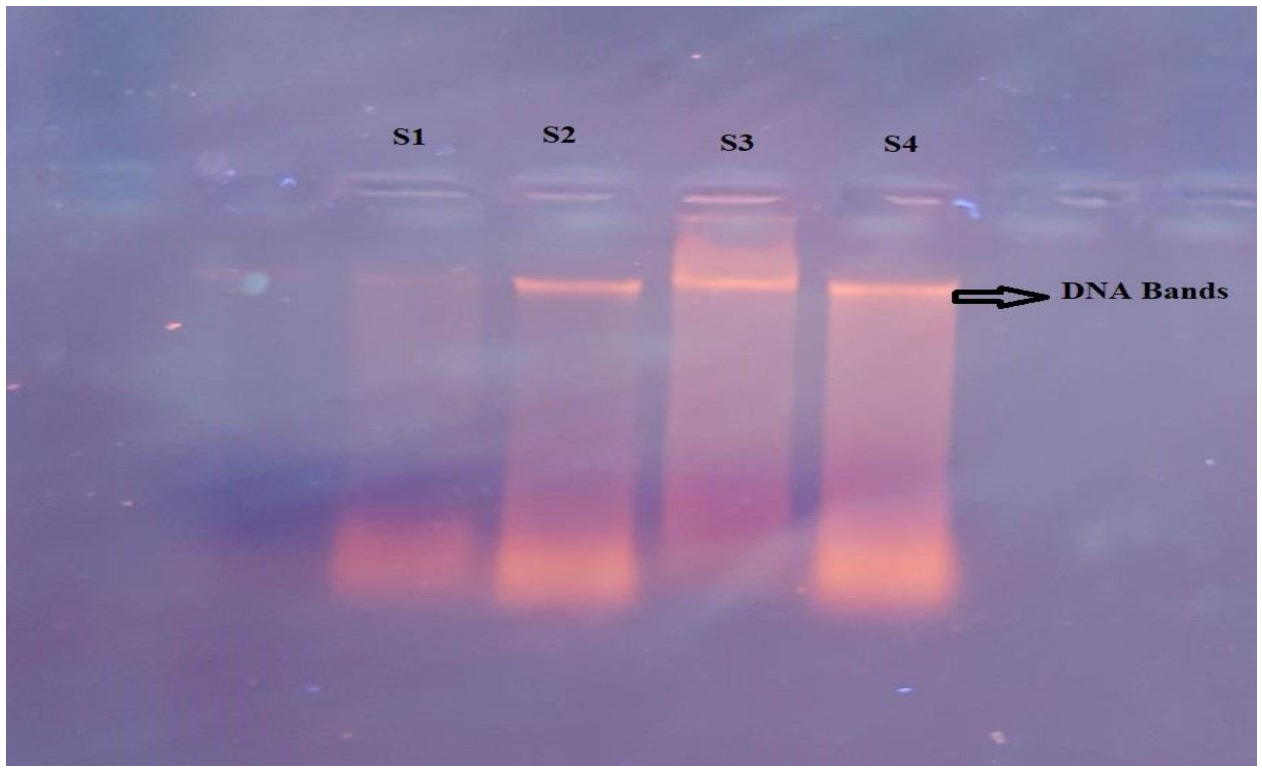

Figure 9. Gel electrophoresis of extracted DNA of isolated strains

Amplified PCR samples were analyzed by using gel electrophoresis. TEM gene was amplified in $100 \%$ strains of S. enterica tested for the presence of antibiotic resistant gene, yielding a strong band as dictated by correlation with size markers keep running on similar gel while no one isolates have CTX-M gene and its presence is 0\% (Fig. 10).

Sample numbers S1, S2, S3, S4 and S5 showed a 508 bp fragment of TEM gene and L (Ladder) showed a 100 bp DNA size marker. Genome sequencing, followed by BLAST, confirmed the presence of TEM gene. The BLAST analysis showed highest similarity (88\% identity) with Klebsiella oxytoca, which also harbors TEM gene (Fig. 11). 


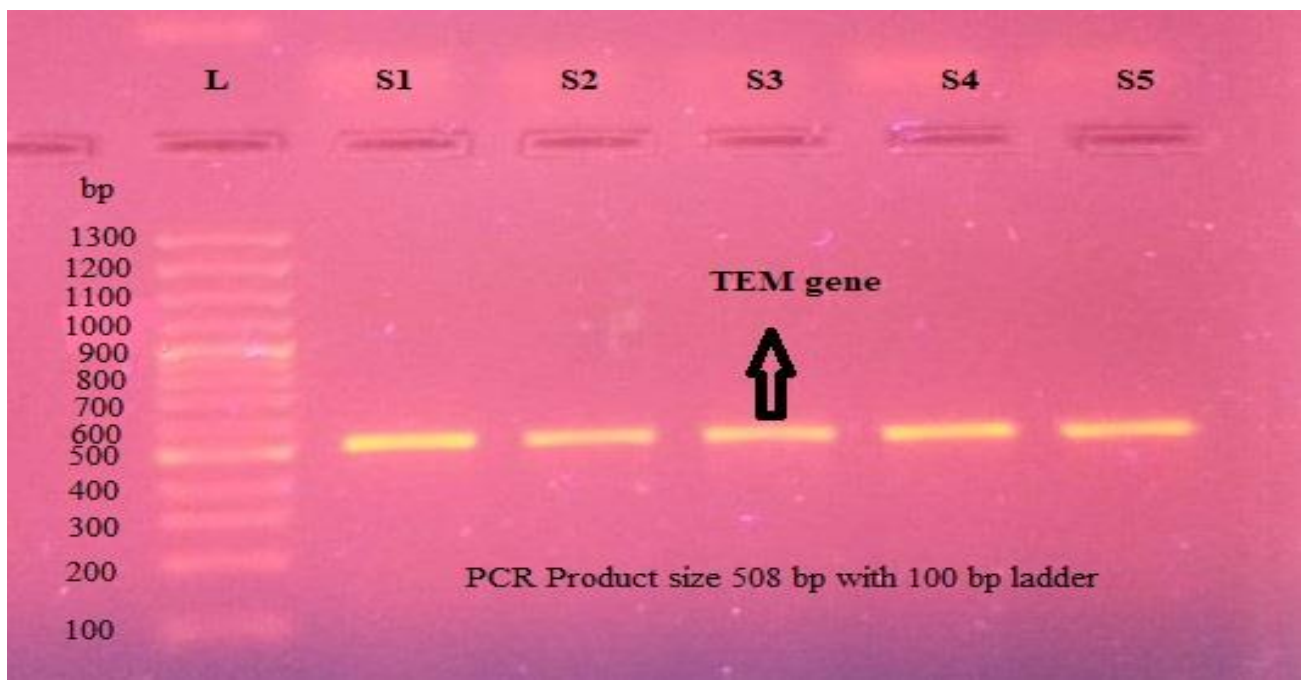

Figure 10. Amplification of TEM gene through polymerase chain reaction (PCR)

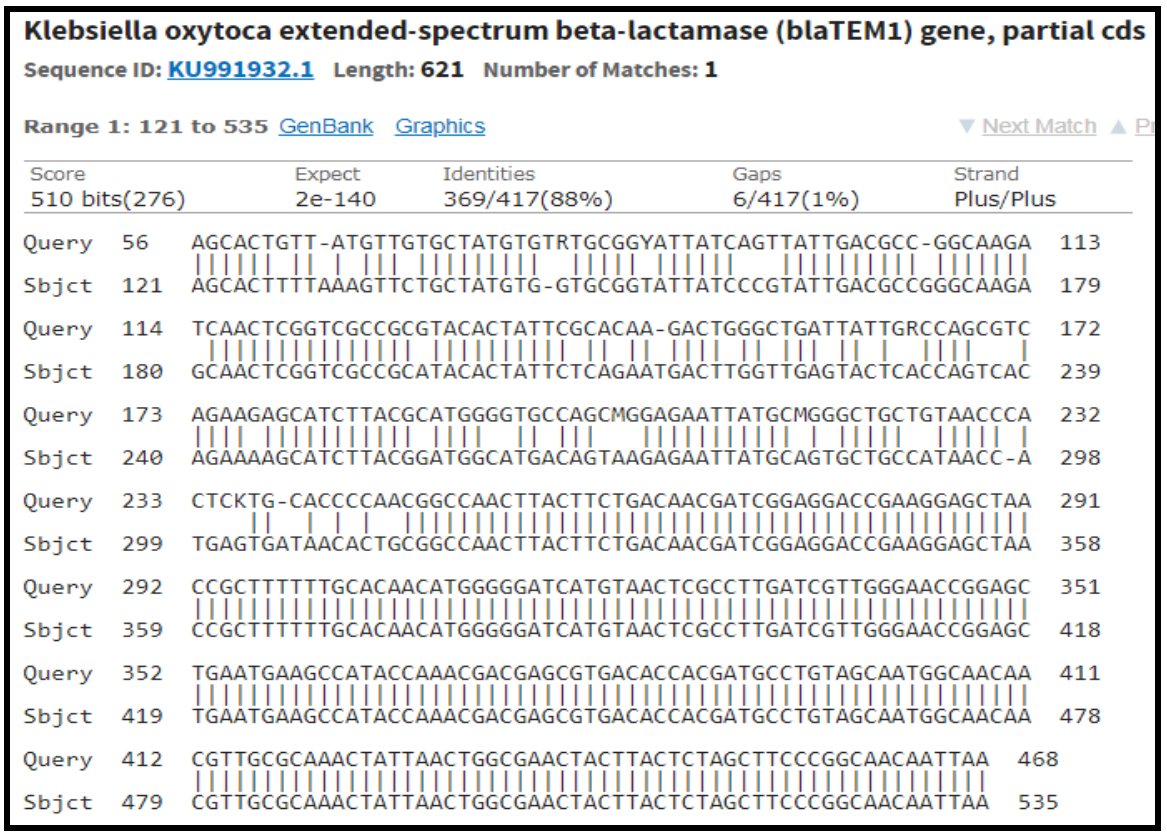

Figure 11. Sequence analysis of TEM gene showing similarity with Gene bank database sequence. Vertical lines represent identical nucleotides

\section{Discussion}

The S. enterica was found higher in oral cavity (43\%) followed by blood (30\%) and intestinal fluid (27\%). The different isolation frequency of Salmonella was due to reason that it was found in oral cavity by eating contaminated food and its presence in blood indicates bacteremia. Experimental studies have demonstrated that gastrointestinal carriages of Salmonella take place in wild birds after disease; hence it is conceivable that healthy birds could be persisting carriers. Samad (2011) declared that Salmonella was transmitted through birds which obtain this infection from their surrounding environment. Present data was identical to the findings of Samad that 
infected birds can play a main role in the transmission of diseases in humans and animals. In current study, among the ten antibiotics used a high rate of antibiotic resistance was observed against penicillin $(93 \%)$, streptomycin $(100 \%)$, erythromycin (93\%) and vancomycin (90\%). Thung et al. (2018) have also discovered comparable outcomes, who found higher prevalance of Salmonella in retail beef meat from different retail markets of Selangor, Malaysia. Antibiotic susceptibility was checked against 15 antibiotics. They also found that all the isolates showed resistance towards penicillin, erythromycin and vancomycin but sensitivity was observed for tetracycline, gentamicin and amoxicillin/clavulanic acid.

TEM gene was present in all positive strains (100\%) tested for the presence of antibiotic resistant gene but CTX-M was absent in these strains and its presence is $(0 \%)$. The presence of TEM gene was further confirmed by genome sequencing which showed $88 \%$ similarity with database sequence of Klebsiella oxytoca by using BLAST. This indicates that $S$. enterica might have acquired TEM gene from $K$. oxytoca. Threfall et al. (2002) reported Salmonella from India and different locations of Asia. They presumed that one of the primary factors of failure of treating Salmonella is because of resistance to ciprofloxacin. Majority of ceftriaxone and ciprofloxacin resistance was the result of activity of $\beta$-lactamase gene which includes CTX-M and TEM gene (Elumalai et al., 2014). Beta-lactamases producing Enterobacteriaceae have progressively developed because of widespread utilization of cephalosporin and represent a major challenge in disease control (Chong et al., 2018). The horizontal gene transfer through wild birds plays an important role in expanding ciprofloxacin and ceftriaxone resistance.

CTX-M gene was not amplified in any S. enterica isolate. This is due to the reason that the universal CTX-M primer used in current study was unable to recognize all positive strains even though showing positive results of resistance to beta lactam drugs. The primers for one group of CTX-M gene were unable to recognize the other groups of CTX-M gene, which results in no amplification of DNA. Pitout et al. (2004) also demonstrated a high level of specificity for the group specific primers.

Wild migratory birds have been recommended as reservoir of beta-lactamase producing pathogenic bacteria in various studies around the world (Bonnedahl et al., 2015; Atterby et al., 2016). Mohsin et al. (2017) indicated beta-lactamase producing $E$. coli in migratory birds along the Indus migration in Pakistan. He revealed that all ESBL-producing E. coli have CTX-M gene as the most prevailing genotype. Study carried out in Korea by Kang et al. (2015) declared that Salmonella enterica subsp. were the infectious agent mostly found in wild birds and brings about mortality in certain species of birds.

\section{Conclusion}

The increase in antimicrobial resistance has turned into a serious issue around the world. It has also been found that migratory birds are playing a main role in the transmission of multidrug resistant pathogens from one place to another. It presents potential risk around the world since these species can easily be utilized as expected and unexpected agents of serious foodborne disease. To avoid the occurrence of antibiotic resistance and MDR Salmonella, it is basic to keep up the continuous checking of antimicrobial resistance and pursue an objective remedy of antimicrobials dependent on local antimicrobial pattern. 


\section{REFERENCES}

[1] Acheson, D., Hohmann, E. L. (2001): Nontyphoidal salmonellosis. - Clinical Infectious Diseases 32(2): 263-269.

[2] Ausubel, F. M., Brent, R., Kingston, R. E., Moore, D. D., Seidman, J. G., Smith, J. A., Struhl, K. (1994): Current Protocols in Molecular Biology. - John Wiley \& Sons, Inc., Chichester.

[3] Atterby, C., Ramey, A. M., Hall, G. G., Järhult, J., Börjesson, S., Bonnedahl, J. (2016): Increased prevalence of antibiotic-resistant E. coli in gulls sampled in Southcentral Alaska is associated with urban environments. - Infection Ecology \& Epidemiology 6(1): 32334.

[4] Berendonk, T. U., Manaia, C. M., Merlin, C., Fatta-Kassinos, D., Cytryn, E., Walsh, F., Bürgmann, H., Sørum, H., Norström, M., Pons, M. N., Kreuzinger, N. (2015): Tackling antibiotic resistance: the environmental framework. - Nature Reviews Microbiology 13(5): 310.

[5] Bonnedahl, J., Stedt, J., Waldenström, J., Svensson, L., Drobni, M., Olsen, B. (2015): Comparison of extended-spectrum $\beta$-lactamase (ESBL) CTX-M genotypes in Franklin Gulls from Canada and Chile. - PLoS One 10(10): e0141315.

[6] Brenner, F. W., Villar, R. G., Angulo, F. J., Tauxe, R., Swaminathan, B. (2000): Salmonella nomenclature. - Journal of Clinical Microbiology 38(7): 2465-2467.

[7] Chong, Y., Shimoda, S., Shimono, N. (2018): Current epidemiology, genetic evolution and clinical impact of extended-spectrum $\beta$-lactamase-producing Escherichia coli and Klebsiella pneumoniae. - Infection, Genetics and Evolution 61: 185-188

[8] Elumalai, S., Muthu, G., Selvam, R. E. M., Ramesh, S. (2014): Detection of TEM-, SHVand CTX-M-type $\beta$-lactamase production among clinical isolates of Salmonella species. Journal of Medical Microbiology 63(7): 962-967.

[9] Foti, M., Rinaldo, D., Guercio, A., Giacopello, C., Aleo, A., De Leo, F., Fisichella, V., Mammina, C. (2011): Pathogenic microorganisms carried by migratory birds passing through the territory of the island of Ustica, Sicily (Italy). - Avian Pathology 40(4): 405409.

[10] Gangoué-Piéboji, J., Bedenic, B., Koulla-Shiro, S., Randegger, C., Adiogo, D., Ngassam, P., Ndumbe, P., Hächler, H. (2005): Extended-spectrum- $\beta$-lactamase-producing Enterobacteriaceae in Yaounde, Cameroon. - Journal of Clinical Microbiology 43(7): 3273-3277.

[11] Gourmelon, M., Caprais, M. P., Mieszkin, S., Marti, R., Wery, N., Jardé, E., Derrien, M., Jadas-Hécart, A., Communal, P. Y., Jaffrezic, A., Pourcher, A. M. (2010): Development of microbial and chemical MST tools to identify the origin of the faecal pollution in bathing and shellfish harvesting waters in France. - Water Research 44(16): 4812-4824.

[12] Herikstad, H., Motarjemi, Y., Tauxe, R. V. (2002): Salmonella surveillance: a global survey of public health serotyping. - Epidemiology \& Infection 129(1): 1-8

[13] Kaftandzieva, A., Trajkovska-Dokic, E., Panovski, N. (2011): Prevalence and molecular characterization of extended spectrum beta-lactamases (ESBLs) producing Escherichia coli and Klebsiella pneumoniae. - Prilozi 32(2): 129-41

[14] Kang, M. S., Jeong, O. M., Kim, H. R., Jang, I., Lee, H. S., Kwon, Y. K. (2015): Arthritis in an egret (Egretta intermedia) caused by Salmonella Typhimurium and its potential risk to poultry health. - Journal of Wildlife Diseases 51(2): 534-537.

[15] Maeda, Y., Tohya, Y., Nakagami, Y., Yamashita, M., Sugimura, T. (2001): An occurrence of Salmonella infection in cranes at the Izumi Plains, Japan. - Journal of Veterinary Medical Science 63(8): 943-944.

[16] Malorny, B., Hauser, E., Dieckmann, R. (2011): New Approaches in Subspecies-Level Salmonella Classification. - Salmonella - From Genome to Function. Caister Academic Press, Norfolk, pp.1-23 
[17] Mohsin, M., Raza, S., Schaufler, K., Roschanski, N., Sarwar, F., Semmler, T., Schierack, P., Guenther, S. (2017): High prevalence of CTX-M-15-Type ESBL-producing E. coli from migratory avian species in Pakistan. - Frontiers in Microbiology 8: 2476.

[18] Pitout, J. D., Hossain, A., Hanson, N. D. (2004): Phenotypic and molecular detection of CTX-M- $\beta$-lactamases produced by Escherichia coli and Klebsiella spp. - Journal of Clinical Microbiology 42(12): 5715-5721.

[19] Radhouani, H., Silva, N., Poeta, P., Torres, C., Correia, S., Igrejas, G. (2014): Potential impact of antimicrobial resistance in wildlife, environment and human health. - Frontiers in Microbiology 5: 23.

[20] Refsum, T., Handeland, K., Baggesen, D. L., Holstad, G., Kapperud, G. (2002): Salmonellae in avian wildlife in Norway from 1969 to 2000. - Appl. Environ. Microbiol. 68(11): 5595-5599.

[21] Samad, M. A. (2011): Public health threat caused by zoonotic diseases in Bangladesh. Bangladesh Journal of Veterinary Medicine 9(2): 95-120.

[22] Threlfall, E. J. (2002): Antimicrobial drug resistance in Salmonella: problems and perspectives in food-and water-borne infections. - FEMS Microbiology Reviews 26(2): 141-148.

[23] Thung, T. Y., Radu, S., Mahyudin, N. A., Rukayadi, Y., Zakaria, Z., Mazlan, N., Tan, B. H., Lee, E., Yeoh, S. L., Chin, Y. Z., Tan, C. W. (2018): Prevalence, virulence genes and antimicrobial resistance profiles of Salmonella serovars from retail beef in Selangor, Malaysia. - Frontiers in Microbiology 8.

[24] Tindall, B. J., Grimont, P. A. D., Garrity, G. M., Euzeby, J. P. (2005): Nomenclature and taxonomy of the genus Salmonella. - International Journal of Systematic and Evolutionary Microbiology 55(1): 521-524.

[25] White, D. G., Zhao, S., Simjee, S., Wagner, D. D., McDermott, P. F. (2002): Antimicrobial resistance of foodborne pathogens. - Microbes and Infection 4(4): 405412. 